bibliography to our paper. The Archives of Locally Based Perinatal Surveys by Diana Elbourne and Lesley Mutch (June 1984) from the National Perinatal Epidemiology Unit at the Radcliffe Infirmary, Oxford, makes reference to no less than 117 studies in England and Wales, and 19 in Scotland.

The dual purpose of our paper was to describe and discuss the feasibility of a possible model for use in a district health authority. Our research model is now being adopted as a service procedure in the Exeter District Health Authority. The resource implications are one consultant session per week (in practice this session is being shared by two consultants-one half session per week each-who act as alternate chairman for each confidential inquiry), the appointment of a half time health visitor to carry out the home visits, and part time medical secretarial help provided without additional cost by the existing secretariat of the District Medical Officer's staff. This expenditure is not large for the purposes which can be achieved.

\section{Clinical features and prognosis of Reye's syndrome}

Sir,

The paper by Glasgow' raises questions as to the homogeneity of the 23 children reported as having Reye's syndrome as the prodromal illness was not biphasic in all; persistent vomiting was not a feature in some; seizures occurred in stages II and III in 14; the liver was not pathologically large in 12; and some did not have appreciable increases in ammonia or transaminases, or both. Thus, it is likely that neither the diagnostic criteria nor the Lovejoy classification (where seizures occur in stage $\mathrm{V}$ and less often in stage IV) could have been applicable to some of these children.

Among the 23 children there may be a phenotype we have described as Singapore syndrome, ${ }^{2}$ that is a Reye's syndrome-like illness with early seizures. ${ }^{3}$ In our report of 20 children, ${ }^{4}$ there was no mortality, and none required 'prophylactic' hyperventilation, intracranial pressure monitoring, mannitol, or barbiturate coma. Advocating invasive management of children in stage II Singapore syndrome is therefore questionable.

J E J Aiyathural and H B Wong University Department of Paediatrics, Singapore General Hospital, Singapore 0316

\section{Dr Glasgow comments:}

I am very grateful for Dr Aiyathurai's interest in and comments on my recent paper ${ }^{1}$ which detailed four years' experience of Reye's syndrome in Northern Ireland.
Firstly I should like to clarify that all of the 23 patients more than fulfilled the diagnostic criteria for Reye's syndrome, as used by both the Boston workers ${ }^{5}$ and the British Paediatric Association-Public Health Laboratory Service surveillance study. ${ }^{\circ}$ These criteria are more stringent than those used by Corey and colleagues during the 1974 epidemic of Reye's syndrome in the United States. ${ }^{7}$ The one patient who did not have appreciably elevated transaminases did, however, have an increased blood ammonia concentration, a very prolonged prothrombin time, and a compatible clinical history, and the necropsy findings also supported the diagnosis.

Secondly, there is a degree of variation within the diagnostic criteria in clinical presentation, degree of biochemical abnormality, complications, and outcome. Vomiting, for example, is a variable symptom which may be changed by a mother's persistence in offering feeds or the sick child's ability to drink. In my experience the consistency of the liver is a more telling clinical sign than hepatomegaly.

Thirdly, only 11 of 23 patients had seizures-two were judged to be in Lovejoy stage II and the rest in stage III or higher. There are two possible reasons for seizures occurring earlier than stage IV or V:

(1) In 22 of our 23 patients hypoglycaemia was found and this seems to increase the likelihood of seizures.

(2) Paediatric staff in peripheral hospitals in Northern Ireland are, in general, very familiar with the symptoms of Reye's syndrome, which makes early diagnosis and, therefore, treatment possible at a stage when recovery is more likely. Patients who have seizures, however, tend to do less well than those who do not have them

I would dispute, therefore, the suggestion that for some of our 23 patients the diagnostic criteria do not apply. It seems less important, however, that cases of Reye's syndrome conform strictly to the stages described by Lovejoy and colleagues. ${ }^{5}$ Our current practice is to emphasise four key aspects of neurological function which we find to be more useful clinically than the composite staging that can be derived from them. (Table)

Aiyathurai and colleagues have previously described the Singapore syndrome ${ }^{2}$ in which children were admitted to hospital with pyrexia, seizures, and features of encephalopathy suggestive of Reye's syndrome. These children had a much better outcome, however, considering that their treatment was mostly conservative. It is difficult to make a fuller comparison between our experience of the two syndromes as technical constraints have limited the pub-

Table Central nervous system modified Lovejoy staging

\begin{tabular}{|c|c|c|c|c|}
\hline Stage & $\begin{array}{l}\text { Level of } \\
\text { consciousness }\end{array}$ & Respiration & $\begin{array}{l}\text { Response to } \\
\text { pain }\end{array}$ & Pupils \\
\hline I & Drowsy & Normal & Appropriate & Normal \\
\hline II & Restless/agitated & Rapid & Appropriate & Normal \\
\hline III & Light coma & Rapid & Decorticate & Normal \\
\hline IV & Deeper coma & Variable & Decerebrate & $\begin{array}{l}\text { Fixed } \\
\quad \text { dilated }\end{array}$ \\
\hline V & Deeper coma & Apnoeic & Flaccid & $\begin{array}{l}\text { Fixed, } \\
\text { dilated }\end{array}$ \\
\hline
\end{tabular}


lished biochemical data about Singapore syndrome. (Blood glucose concentrations were less than $2.8 \mathrm{mmol} / \mathrm{l}$ in 6 of 14,7 of 18 had a two to three fold rise in transaminase activity, 2 of 12 had coagulation abnormalities, but blood ammonia values were not reported.) Seizures, the most common presentation of Singapore syndrome, occurred in $48 \%$ (11 of 23 ) of my Reye's syndrome patients.

From a study of their published work and in personal discussions several years ago, it is my impression that Aiyathurai and colleagues have described a separate, quite distinct syndrome, possibly more akin to the febrile seizure than to Reye's syndrome. The differences, particularly in clinical presentation, laboratory data, and prognosis, given the conservative approach to management, make it unlikely that Singapore syndrome is a subgroup of the syndrome described by Reye et al. ${ }^{8}$

Finally, a note of caution to those who continue to use a 'wait and see' policy in stage II Reye's syndrome; it is an unpredictable and unforgiving disorder. Despite intensive care and vigorous measures to control intracranial pressure using 'prophylactic' hyperventilation etc, $25 \%$ of the Belfast patients died or incurred severe, permanent neurological damage.
References

1 Glasgow JFT. Clinical features and prognosis of Reye's syndrome. Arch Dis Child 1984;59:230-5.

2 Aiyathurai JEJ, Mathew T. Wong HB. Reye's syndrome and the Singapore syndrome. J Singapore Paediatr Soc 1978;20: 159-67.

3 Aiyathurai JEJ. A Reye's syndrome-like illness with early seizures: its relationship to Reye's syndrome. J Singapore Paediatr Soc 1982:24:33-53.

4 Aiyathurai JEJ. A Reye's syndrome-like illness with early onset seizures - Singapore syndrome. (Abstract). 6th Asian and Oceanian Congress of Neurology 1983:S74:49.

${ }^{5}$ Lovejoy FH, Jr, Smith AL, Bresnan MJ, Wood JN, Victor DI, Adams PC. Clinical staging in Reye syndrome. Am J Dis Child 1974;128:36-41.

- Reye's syndrome in the British Isles: first annual report of the joint British Paediatric Association and Communicable Disease Surveillance Centre surveillance scheme. $\mathrm{Br}$ Med J 1984;228:548-50.

7 Corey L, Rubin RJ, Hattwick MAW, Noble GR. Cassidy E. A nationwide outbreak of Reye's syndrome. Its epidemiologic relationship to influenza B. Am J Med 1976:61:615-25.

* Reye RDK, Morgan G, Baral J. Encephalopathy and fatty degeneration of the viscera. A disease entity in childhood. Lancet 1963 ;ii: $749-752$.

\section{Book reviews}

Clinical Atlas of Human Chromosomes. 2nd ed. By J de Grouchy and C Turleau. Pp 488: $£ 56.50$ hardback. John Wiley, 1984.

The first edition of this book in 1977 established it as the authoritative text on the nature of human chromosomal defects and the clinical syndromes they produce. This second edition has 176 more and bigger pages and includes the discoveries of the intervening years. Eighty six individual or groups of conditions are now described and illustrated fully with clinical photographs. Each autosome has its own chapter, while that on the sex chromosomes contains information on 10 sex chromosome anomalies as well as pieces on true and pseudo-hermaphroditism, mental retardation, and fragile $\mathrm{X}$-syndrome. There is also a section on polyploidy followed by seven useful appendices on chromosomal techniques, dermatoglyphics, terms used in clinical description, types and mechanism of formation of chromosomal aberrations, chromosomal nomenclature, the human gene map, and syndrome finding. Every chapter is prefaced by models of the relevant chromosome, with bands and numbers of increasing complexity that allow the position of breakage and site of genetic markers to be broadly assigned. There follows a list of single gene diseases coded on that chromosome as well as a more complex list of known markers with their positions. The clinical features of each syndrome are summarised and then detailed systematically. There are selected references. Comments on the cytogenetic study, dermatoglyphics, and laboratory findings follow.

This book does not have any serious contenders and now that the peak of chromosomal discovery seems past it is likely to remain the main reference text for paediatricians, clinical geneticists, and cytogeneticists for many years to come. It is obviously more exhaustive than the chromosome section in the third edition of Smith's Congenital Malformations in Man and should be considered complementary to that volume. For those paediatricians who like the diagnostic challenge of the dysmorphic and retarded child, and for those who would like to interpret the chromosomal material they receive, this is an essential volume. It certainly will be most welcomed by the clinical geneticists who want to look beyond the microscope. A first class and beautifully produced volume.

J INSLEY
Progressive Spinal Muscular Atrophies. International Review of Child Neurology series. Edited by I Gamstrop and $\mathrm{H}_{\mathrm{B}}$ Sarnat. Pp 250: $\$ 60.00$ hardback. Raven Press, 1984.

The spinal muscular atrophies are common compared with most genetic disorders, almost equalling the muscular dystrophies in their incidence; they are confusingly variable in their presentation, and poorly covered in most paediatric texts. A scholarly monograph, therefore, especially one by the acknowledged experts gathered here by Drs Gamstrop and Sarnat, is most welcome. As a summary of recent knowledge it is admirable; yet it has some disappointing features. Almost every chapter has its own approach to classification, a serious error when confusion in classification is already one of the most problematic features of this group of disorders. The format of the book is odd too. There is a series of useful chapters on the clinical features, pathology, electrophysiology, use of ultrasonography, treatment, role of parent group therapy in management, and strategies for research, but each chapter is followed by another called a 'commentary' which tries to contrive a different tack but inevitably covers some of the same ground 